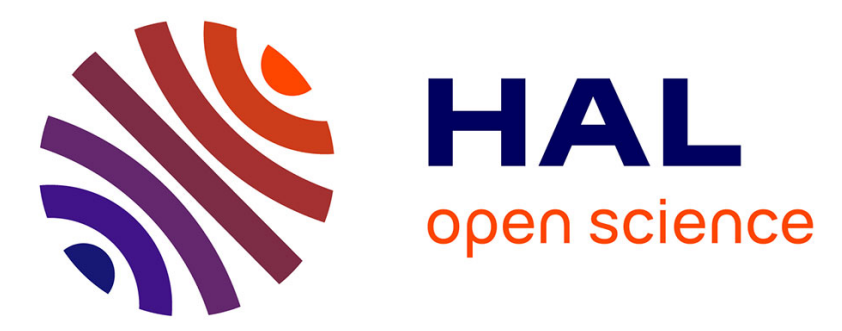

\title{
A Cognitive-Pragmatic Model for the change from single-word to multiword speech: A constructivist approach
}

Edy Veneziano

\section{- To cite this version:}

Edy Veneziano. A Cognitive-Pragmatic Model for the change from single-word to multiword speech: A constructivist approach. Journal of Pragmatics, 2013, 56, pp.133-150. 10.1016/j.pragma.2013.03.013 . halshs-00839522

\author{
HAL Id: halshs-00839522 \\ https://shs.hal.science/halshs-00839522
}

Submitted on 17 Jul 2015

HAL is a multi-disciplinary open access archive for the deposit and dissemination of scientific research documents, whether they are published or not. The documents may come from teaching and research institutions in France or abroad, or from public or private research centers.
L'archive ouverte pluridisciplinaire HAL, est destinée au dépôt et à la diffusion de documents scientifiques de niveau recherche, publiés ou non, émanant des établissements d'enseignement et de recherche français ou étrangers, des laboratoires publics ou privés.

\section{()ㅜ) $\Theta$}

Distributed under a Creative Commons Attribution - NoDerivatives| 4.0 International 


\section{A Cognitive-Pragmatic Model for the change from single-word to multiword speech: A constructivist approach}

Edy Veneziano

Université Paris Descartes - CNRS, MoDyCo, UMR 7114

Address for correspondence

Edy Veneziano

Institut de Psychologie - bureau 4075

Université Paris Descartes

71, Avenue Edouard Vaillant

92100 Boulogne Billancourt

France

edy.veneziano@parisdescartes.fr

\section{Abstract}

What brings children to gradually replace single-word with multiword utterances? The Cognitive-Pragmatic Model (CPM) presented is based on the idea that single-word utterances are a well-anchored behavior and considers that the change from single word to multiword speech requires a conceptual change in the way children apprehend the relationship between communicative intentions and their verbal expression. The CPM proposes that two phenomena, expressive options and co-constructed SSWUS (conversationallygenerated (ConvG) SSWUs and discourse-sustained child-generated (ChG) SSWUs), provide the initial steps in the transition to multiword speech. The CPM predicts that children 1) start showing expressive options and producing ConvGSSWUs and ChG-SSWUs sustained by immediately previous discourse; 2) all kinds of SSWUs appear before multiword utterances; 3) before multiword utterances become dominant, children rely often on conversation and/or on immediately previous discourse to produce SSWUs or multiword utterances; and 4) across-turns ChG-SSWUs appear before within-turn ChG-SSWUs. The predictions of the CP Model were confirmed by the longitudinal data of two French-acquiring children observed during spontaneously-occurring interaction. The implications of the CPM and issues requiring further investigation are identified and discussed.

Keywords

multiword speech, transitional phenomena, conversation, discourse, expressive options, SSWUs 


\section{A Cognitive-Pragmatic Model for the change from single-word to multiword speech: A constructivist approach}

\section{INTRODUCTION}

The combination of words into a larger unit of meaning is a landmark development. It is a considerable change in the meaning relation of words. Meaning relations do not hold only between words and their referents but a new relation is installed also between the words themselves, a language-to-language relation that Tesnière described as the "third element" (Tesnière, 1959:12).

Most children produce their first multiword utterances after they have produced utterances containing only one meaningful word. Recent analyses focusing on children's multiword utterances find relations between children's early multiword productions and what they said or heard earlier (Lieven, Salomo \& Tomasello, 2009). Accordingly, multiword utterances reflect specific and concrete strings children have heard and stored in memory (Tomasello 2003). But how does the change from single word to multiword utterances in children's speech occur? How is it that children - at a certain point in their language development - start to combine words to communicate meanings and functions they were expressing before with utterances containing only one meaningful word?

Single-word and multiword speech are considered to be in developmental continuity. In a strong continuity approach, single words are considered the surface expression of a richer underlying structure of which only one element is verbalized (e.g. Antinucci \& Parisi, 1973), or are considered to express different semantic relations by combining with situational elements (e.g. Greenfield \& Smith, 1973). In another type of continuity, single word utterances are not granted more structural complexity than allowed by their surface value. Their link to multiword utterances 
is seen in the progression of relational meanings they express (e.g. Bloom, 1970; Rodgon, 1976; Dore, 1985; Werner \& Kaplan, 1963). For example, when children say 'daddy' while pointing at daddy's shoes, the meaning expressed is not referential but relational: relative to the object pointed, it expresses a possessive or associative relation (Dore, 1985). Another kind of continuity is seen in sequences of single word utterances, known as Successive single-word utterances or SSWUs. These sequences, considered to bridge the gap between single word and multiword utterance (e.g., Bloom, 1973; Greenfield \& Smith, 1976; Ochs et al., 1979; Scollon, 1979; Veneziano, Sinclair \& Berthoud, 1990), are single words that follow each other closely across turns, expressing one communicative intent.

Developmental changes in the use of single word utterances and transitional phenomena like SSWUs suggest that the change between single word and multiword speech presents continuities with earlier behaviors but the nature of these transitional phenomena in the change remain to be well understood. What kinds of changes are brought about by these behaviors and why do they occur? In this paper we will primarily focus on the what sets in motion the change leading children to revise their way of communicating verbally.

Here we start from the idea that children do not view single word speech as inadequate but rather as a conquest that they are eager to use. Indeed, single word utterances are a well-grounded manner of communicating that can last for a relatively long time. From the time children start producing a few recognizable words, it may take as long as 12 months for the change to take place (Acredolo et al., 1999). During this period, children seem to be guided by an underlying implicit idea according to which one word suffices to express their intended meaning. 
This paper focuses on the developments that can stir up this "sufficiency" hypothesis and change the way children apprehend the relation between words and the meanings expressed. It proposes a cognitive-pragmatic model (hitherto, CPM) that emphasizes the importance of two phenomena: variation in expression or expressive options (e.g., Berman \& Slobin, 1994; Veneziano, 2008) and coconstructed SSWUs (e.g., Veneziano, 1999). It will be argued that these two phenomena do not provide just additional evidence for continuity between single words and multiword speech but provide relevant ways leading children to revise their implicit ideas on the relation between single word utterances and the meanings they express.

Before presenting the CP Model in detail, we will briefly discuss the singleword period and in particular three aspects considered to be involved in the change from single-word to multiword utterances: communicative needs, articulaory fluidity and the mismatch between what children produce and what they hear in adults' utterances. It will be argued that although these aspects eventually contribute to the change, they cannot be considered its primary motor.

\subsection{The single-word utterance period.}

As mentioned, for many children the production of utterances containing only one meaningful word lasts for a relatively long period of time. The communicative efficiency of the single-word utterances and the long development in phonological and articulatory mastery might contribute to the relative length of the single-word period.

1.1.1. The communicative strengths of single-word utterances

Children can express various meanings and communicative functions with single-word utterances (e.g. Bretherton, 1988; Barrett, 1989; Ninio, 1994; Clark, 
2009). They start using them to express requests and to share attention and, with development, children come to use single-word utterances to express an increasingly wide variety of communicative functions, some of them quite complex and implying decontextualized speech, like justifying requests and refusals, and making references to past and future events (e.g. Sachs, 1983; Shatz, 1994; Veneziano \& Sinclair, 1995). The intended meanings of children's single-word utterances are quite often well understood by the familiar environment who can rely also on previous discourse and on shared experience. Snow (1978) reports an 18 months old child saying bandaid several times. The observer couldn't understand what the child meant but the mother, who shared the past experience with the child, understood very well and interacted with the child stimulating her to elaborate on her intended meaning. Even complex functions like justifications are interpreted as such, as shown by the fact that mothers accept children's position much more often when their refusals are justified than when they are not (Dunn \& Munn, 1987; Dunn,1991; Veneziano, 2001).

Given the settings of production, the limited needs of the children and the collaborative adults, single word utterances meet fairly well children's communicative needs. Thus communicative pressure might not be the primary motor leading children to move onto multiword speech, although the later will become useful for more precise and richer expressions of chilren's intended meanings and functions.

\subsubsection{Phonological and articulatory complexity}

Also the complexities of articulation (cf. Smith, 1988; Thelen, 1991) and the slow development of articulatory fluidity contribute to the length of the single word period (e.g., Clark, 2009). It takes time to get good motor control for articulating 
correctly a target word. Moreover, children's productions are at first limited by preferences for some sounds and sound sequences (e.g., Ferguson \& Farwell, 1975; Elbers \& Ton, 1985). Difficulties in articulation are evidenced also by the fact that children's pronunciation of a word is better when it is produced in isolation than when it is part of a longer utterance (e.g. Donahue, 1986; Matthei, 1989).

Phonological mastery and articulatory fluidity are certainly skills that are necessary for children to start producing two word utterances, but are they sufficient? We assume that they are not. Before children start using multiword utterances, they can produce strings that contain more than one meaningful word, by adding "dummy forms" (e.g., Barrett, 1989; Cutler \& Swinney, 1987; Dore, Franklin, Miller \& Ramer, 1976; Bloom, 1973; Galligan, 1987), filler elements (Bassano \& Eme, 2001; Kilani-Schoch \& Dressler, 2001; López Ornat, 2001; Peters \& Menn, 1993; Taelman et al., 2009; Veneziano, Sinclair \& Berthoud, 1990; Veneziano \& Sinclair, 2000) or produce two meaningful words articulated as a two word utterance referring however each to a different communicative intention (e.g., Veneziano et al, 1990). We suppose that conceptual and linguistic developments are needed in order to use articulatory abilites to produce multiword utterances.

\subsection{The mismatch between children's and adults' productions}

Children can learn from the comparison between their own and the environment's speech, in particular from adult's contingent replies (e.g. Chouinard and Clark, 2003; Veneziano \& Parisse, 2010). The mismatch between the two may contribute to the change from single-word to multiword speech. Indeed, even though child-directed speech (CDS) has been found to be shorter and to contain single-word utterances in greater quantity than found in adult-to-adult speech (Ninio, 1992), CDS doesn't offer a predominant single-word speech model and 
children have plenty of opportunities to apprehend the mismatch between their output and the input. Thus, if mismatch were a primary motor, we shouldn't expect single word utterances to last so long. Also, if children adjusted their production to improve the match between their productions and the input, we should expect them to produce alongside single-word utterances, also utterances containing two or more content words, as well as utterances containing articles, adjectives, modals or prepositions. However this is not the case. Changes in children's production do not occur haphazardly but concern particular aspects of their production at particular times. Moreover, the early two-word utterances that gradually replace single-word speech are only slightly better approximations of adult utterances.

Growing communicative needs, phonological and articulatory developments as well as the mismatch between the child's and the adult's productions all contribute to the eventual change to multiword speech. So do the growing cognitive and planning capacities of children. However, we think that these components are necessary but not sufficient to set the change in motion. Here we emphasize that the change in production necessitates a change in the mind, a different representation of the relation between utterances and their intended meanings. The CP Model is proposed to address this issue.

1.4. A cognitive-pragmatic model (CPM) for the change from single to multiword speech

The CP Model emphasizes the importance of two phenomena: variation in single-word utterances or the availability of expressive options (e.g., Berman \& Slobin, 1994; Veneziano, 2008) and co-constructed SSWUs (e.g., Veneziano, 1999). These two phenomena exemplify a Piagetian-type of constructivist account of continuity by which higher-level behaviors (here multiword utterances) are seen 
to grow out from the possibilities offered by the behaviors of the lower level (here single word utterances) (see, for example, Piaget \& Garcia, 1983/1989). The main idea is that children's increasing competence as single-word speakers creates ways of functioning that eventually lead children to revise their implicit ideas on the relation between single word utterances and the meanings they express.

1.4.1. Changing Single-Word utterances: The development of expressive options.

In one of his latest work, Piaget (1981/1987) looked at cognitive development from the point of view of a growing ability to conceive alternatives. He showed that children increase their knowledge by considering a particular event as one among a set of possible events that were not realized but could have been. At first, alternatives are taken into consideration successively, one after the other; then, children become able to anticipate the different possibilities simultaneously and view them as co-possible alternatives. The empirical studies concerned children between 4 and 12 years of age (Piaget \& Coll., 1981/1987). However, Piaget discusses how this process is at work also in the later sensorimotor period.

Earlier work suggests that this development takes place also for children's early language use.

At first, when children express, within a short time period, similar communicative intentions, they use, from one episode to the next, the same words. Then, children start using different single-word utterances, produced one at a time, to talk about similar communicative intentions. For example, the request to have a mechanical toy work may be expressed once by verbalizing the person to whom the request is addressed (for example, mommy), once by expressing the action that the requested person is supposed to perform or the desired state of the object (for 
example 'turn'). This phenomenon was reported for children acquiring different languages (e.g. Antinucci \& Parisi, 1973; Barrett, 1981; Clark, 1997; Greenfield \& Smith, 1976; Halliday, 1975; Ninio, 1994; Veneziano, 2004).

Why is variation in single-word utterances important for the change from single-word to multiword speech? This behavior prepares multiword utterances by creating links among words that are used successively and adequately to express the same kind of communicative intent. When children show variation, they are still completely single-word speakers, since 00 only one single-word utterance is produced to express a given communicative intention. However, when children have at their disposal alternative expressions, their single word utterances start changing in status. These words become part of a network of expressive options where several words are related to the same communicative intention in a many-toone relationship and start to be also related one to the other by the fact of being all adequate expressions of the communicative intention at hand.

The construction of such a network of relations is considered here an important step towards the inter-words relations of multiword speech.

How do expressive options come about? The supposed cognitive development described above and children's growing ability to shift attention to take into account several aspects of the situation at the same time, might provide an important cognitive basis. Another source for the development in expressive variation, is given by children's growing lexical repertoire (e.g., Veneziano, 2004). As children's lexical repertoire grows, children start to have alternative options to express verbally a given communicative intention, that is, children have at their disposal different words whose meaning fits the communicative intention at hand and can then start using different words to verbalize similar communicative intents. 
With progress in mental representation, shifts in attention can occur more rapidly and expressive options may be activated closer in time (Piaget, 1981). Children may then end up uttering the two semantically-related words for the expression of the same communicative intention (Veneziano, 2004). How many different words are needed to produce variation in single-word utterances? This cannot be set in absolute terms as it may depend on the kinds of words children have at their disposal as well as on the kinds of communicative intentions they express. More than an exact number, we may want to look for an increase in vocabulary, that might denote a conceptual change in the referential status of words (e.g., Barrett, 1989).

1.4.2. Changing Single-Word utterances: Successive single-word utterances.

Another way in which the relation of single-word utterances to the expression of communicative intentions may be revised is through the production of Successive Single Word Utterances (SSWUs). In SSWUs, children produce, in different turns, two or more single-word utterances related to one and the same communicative intention, words that could potentially combine one with the other in a syntagmatic way (Bloom, 1970, 1973). The words may be separated by the intervention of another speaker or by a temporal distance between them (Bloom, 1973; Greenfield \& Smith, 1976; Ochs, Schieffelin \& Platt, 1979; Scollon, 1979; Barrett, 1989; Cohen, 1952/1969; Fonagy, 1972; Ingram, 1979; Veneziano et al., 1990; Veneziano, 1999, 2005; Herr-Israel \& McCune, 2011). Instead of clinging on a particular word, children become capable to decenter and to produce different single-word utterances while keeping focused on the same communicative intention.

\subsubsection{Successive single-word utterances relevant for the initial change}


As it will be detailed in the Method section below, different kinds of SSWUs were identified according to the different types of support children receive from discourse and to the temporal distance separating the single-word utterances composing the sequence (Veneziano, 1999; Herr-Israel \& McCune, 2011). In the CPM, two types of SSWUs are considered particularly relevant for the initial steps:

a) conversationally-generated SSWUs (in short, ConvG-SSWUs) and b) childgenerated SSWUs (in short, ChG-SSWUs).

a) Conversationally-generated $S S W U$ s (ConvG-SSWU). In these SSWUs children receive the greatest support from conversation to produce two (or more) single-word utterances relating to one same communicative intention (Veneziano, 1999). In example 1 below the child starts with the production of one single-word utterance ('child(ren)'). In her following turn, the mother interprets and expands on that single-word. The child shifts her attention to a different word contained in the mother's utterance and, in her following turn, produces a second single-word utterance which is semantically-related to the first:

Example 1 - ConvG-SSWU: imitative

The child points at an image where children on a merry go round

Child $_{1}$ : /afã/ 'enfant(s)' 'child(ren)'

Mother $_{2}$ : les enfants sont en carrousel?

'the children are on the merry-go-round?'

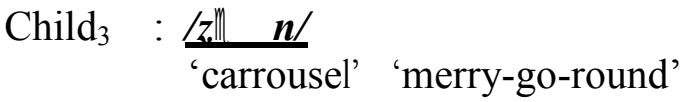

The same effect is obtained when the child, after the production of an initial single-word utterance, replies to his/her partner's question, itself related to the pevious child's turn, as shown in example 2 below:

Example 2 - ConvG-SSWU: elicited

Child holds a plastic chip and looks around him before placing the chip in front of a toy cow

Child $_{1}: /$ su/ 


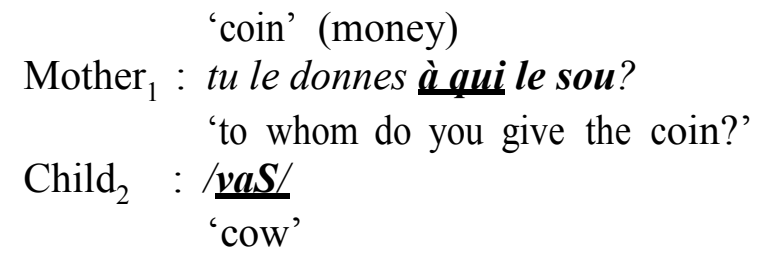

b) Child-generated SSWUs (ChG-SSWUs). The greater availability of expressive options allows children to produce child-generated SSWUs, whereby the child utters the two successive single-word utterances without the lead from the immediately preceding conversational move of the partner. In ChG-SSWUs, either the partner doesn't intervene between the single-word utterances of the sequence (see example 3 below) or, if s/he does, the partner's turn doesn't provide a hint for the production of an additional single-word utterance on the child's part, by uttering it or soliciting it through a question (as this is the case in ConvG-SSWUs), as shown in example 4 below:

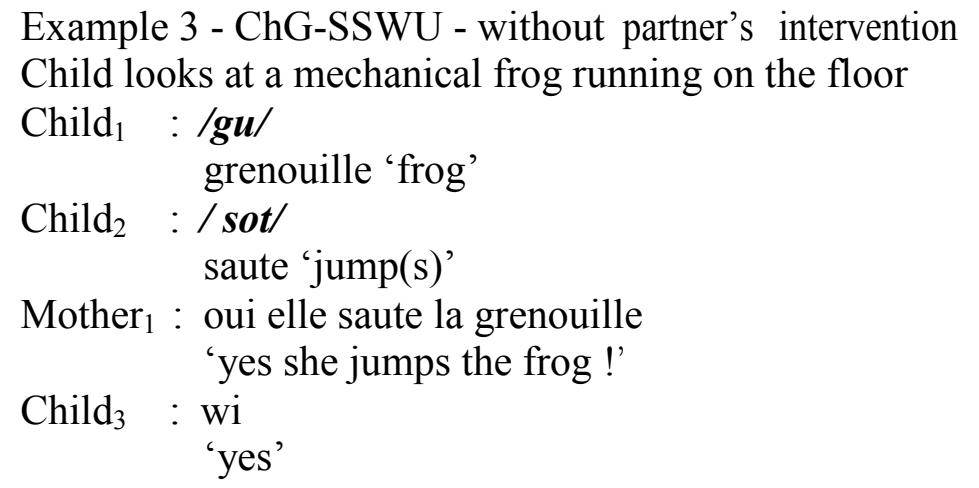

In example 3, the two words of the ChG-SSWU are uttered without any intervention of the partner between them. They are uttered in two different turns, since the pause between them is greater than 2 secs. (see below, under Method, for the definition of turn and for how pauses were measured). This kind of ChG-SSWU is called across-turns.

Example 4 - ChG-SSWU - with neutral partner's intervention The child is close to his mother and looks at two chips - representing coins - in his mother's hand

Child $_{1}$ : lone/ 


\begin{abstract}
donner/donné 'to give/given'
Mother $_{1}$ : je dois te les donner?

'I have to give them to you?'

Child $_{2}$ : / idi /

Edy

Mother $_{2}$ : je dois les donner à Edy?

'I have to give them to Edy?'

In example 4, the mother follows up on each of the two single-word utterances of the sequence produced by the child (the ChG-SSWU is also here across-turns). The mother's behavior is certainly important on an interactional level but doesn't provide any specific hint to the child's verbalization of the second single-word utterance of
\end{abstract} the sequence.

While in ChG-SSWUs children do not receive the immediate lead from the partner to produce the second word of the sequence, they may find support in previous discourse. This is the case when at least one of the single-word utterances of the sequence was uttered in at least one of the three previous theme-related turns, by the partner, by the child, or both. Example 5 below provides an example of within-turn ChG-SSWU where the mother had uttered one of the two words of the sequence -- 'confetti'--, in a previous turn:

Example 5 - Within-turn ChG-SSWU sustained by the partner's previous discourse:

The mother, after cuddling the child, points towards a confetti stuck on the child's leg

Mother1: tu as un confetti là t'as vu?

'you have a confetti there, have you seen?'

Child $_{1}: n h$ ?

Mother $_{2}$ :ouais

'yeah'

Child $_{2}:$ /e've \#\#

enlev/e/ \#\# confetti '(to) remove/removed confetti'

In example 6 below, it is the child who had produced one of the words of the SSWU in a previous turn: 
Example 6 - Within-turn ChG-SSWU supported by the child's previous discourse

Child and mother "read" a picture book. The child turns the pages looking for a particular image

Child $_{1}: \Delta \boldsymbol{e} \mathrm{K}$

cherche 'look for'

Child $_{2}:$ rodil \# $\angle[e\lceil/$

crocodile \# cherche 'crocodile \# look for'

1.4.2.2 Importance of ConvG-and ChG-SSWUs for the change to multiword speech

Why are ConvG-SSWUs and ChG-SSWUs important for the change from single-word to multiword speech? SSWUs prepare multiword utterances by allowing children to take into account and talk about more than one aspect of a situation within a short time period. The conversational framework of ConvGSSWUs allows children to talk about a different aspect of the situation without necessary prior planning since they utter the second single-word utterance of the sequence by following successively the conversational turns (uptaking one element contained in the immediately previous adult's utterance of answering a question asked by the adult). For some children, participation in these exchanges constitutes a privileged way to start verbalizing different aspects of one same situation or communicative intention. Other children may rely also on child-produced SSWUs. Earlier research shows that SSWUs produced without the partner's intervention and, later, two-word utterances, occur first in a discursive context where one of the component words was uttered in the three previous turns, a configuration supposed to reduce the cognitive and memory load on the subsequent production (e.g., Lieven, 1984; Shatz, 1978; Veneziano et al., 1990).

On this ground, the CPM predicts that ConvG-SSWUs and ChG-SSWUs relying on previous discourse should occur first. Also, that across-turns ChG- 
SSWUs should occur before within-turn ChG-SSWUs, the latter requiring more planning and/or more rapidity in attention and in articulation shifts.

1.5. The developmental sequence in the change from single to multiword speech predicted by $C P M$

The cognitive-pragmatic model presented here predicts that the change from single- to multiword speech goes through the following developmental seuqence:

1) Children start expressing similar communicative intentions with different single-word utterances (expressive options). At this time, or soon after, ConvGand/or ChG-SSWUs appear;

2) ConvG- and ChG-SSWUs appear before multiword utterances;

3) ConvG-SSWUs and discourse-sustained ChG-SSWUs are produced more in the initial stages; ChG-SSWUs and multiword utterances not relying on previous discourse become more numerous later;

4) Across-turns ChG-SSWUs appear before within-turn ChG-SSWUs

These predictions will be tested against the data from two longitudinal corpora of spontaneously-occurring mother-child interaction.

\section{METHOD}

\subsection{Participants}

The longitudinal studies of two children, a boy and a girl living in Geneva, Switzerland have been used for this study ${ }^{\mathrm{ii}}$. The girl was the second-born child of two children, her brother being about three years older, while the boy was the first and only child at the time of recording. The social background of the two families was middle-class. The language spoken at home was Geneva French. The 
longitudinal study for each child started from the time children produced a few recognizable words and ended when they produced mainly multiword utterances. With these developmental criteria, the girl was followed from $1 ; 3$ to $2 ; 2$, and the boy from $1 ; 7$ to $2 ; 3$. The different rates of development of the two children will be used here to see whether similarities in developmental trends exist in spite of chronological age.

\subsection{Data collection and transcriptions}

Children were observed at home for about one hour every two weeks, in interaction with familiar partners, particularly the mother and at times one of the observers. The sessions were video and audio recorded with a shoulder-held camera to follow the child as he/she moved about. The sessions included spontaneously occurring free play activities, book reading, symbolic play and, sometimes, snack/coffee around the kitchen table. Two observers (including the author) were present, taking turns at filming and note-taking, while sitting out of the way of the activities, generally assuming a friendly, non-intrusive attitude, but responding when solicited by the child. The sessions were transcribed by one person (one of the observers) and were checked by two other persons. Transcription of the child's speech remained close to actual pronunciation (transcribed in SAMPA); adult speech was transcribed in conventional French orthography. Transcripts include detailed information about non-verbal activities that contributed to the understanding what was said. Transcriptions were recently adapted to CHAT format and linked to the videorecordings. On this occasion they were checked again and disagreements were reviewed and usually settled through further listening and viewing of the movies.

\subsection{Data analysis}


The analysis aimed to identify the occurrence of expressive options and of different kinds of SSWUs and multiword utterances.

\subsubsection{Preliminary definitions}

A turn: A vocal sequence uninterrupted by another speaker's intervention or by a pause greater than 2 seconds $\mathrm{sii}^{\mathrm{ii}}$.

A word: The child's vocal production was considered a word if it had some phonological resemblance to a word of the language and if its meaning was shared by the child and at least his/her mother. These judgments were based on close scrutiny of the transcripts and videotapes, taking into consideration preceding and subsequent discourse and situational context, and all the nonverbal happenings at the time of the verbalization. The mother's interpretation also helped in word identification, particularly in the early period. This classification is based on earlier work (Veneziano, 1981; Vihman \& McCune, 1994) that explicitly takes into account the degree of match between the adult's and the child's forms (minimally, we required a syllabic match), the conversational sequence in which the child's form occurred, the overall pattern of the mother's interpretation (whether consistently as a particular word or variably as one word or another), the plausibility of the word's meaning in the situation at hand, and the overall consistency in the child's use of a particular form.

2.3.2. Expressive options: In order to establish whether children used the same or different single-word utterances to express similar communicative intentions occurring at different times, we first established criteria of similarity. In earlier work (e.g. Antinucci \& Parisi, 1973; Barrett, 1981; Clark, 1997; Greenfield \& Smith, 1976; Halliday, 1975; Ninio, 1994), similarity was based on speech acts (e.g., requesting and asserting) or on more narrowly-defined functions that could 
however concern different situations. For example, Ninio (1994) considered communicative intents like "initiating joint activity on a focused object" in which the activity and the focused object depended on the specific situations in which they occurred. Here, to ensure a maximum of similarity among the episodes, we considered «similar» only occurrences of narrowly-defined communicative intentions. For example, occurrences of 'making a request to have a spinning top turn', were considered similar to each other and at the same time different from communicative intentions like 'making a request to take plastic beads apart' or 'putting a coin into a truck'. To be analysed for expressive variation, a communicative intention had to have at least two occurrences during the same observational session. Moreover, since we were interested in the transitional period, only episodes occurring before the appearance of two-word utterances were included in the analysis. Thus, the developmental period analyzed for the girl ran from $1 ; 3$ to $1 ; 7$ and that for the boy from $1 ; 6$ to $1 ; 11$.

Expressive variation was considered to take place if the child expressed occurrences of similar communicative intentions with different single-word utterances. As mentioned, at least two occurrences of the communicative intention must have been observed within the same session. The similar communicative intentions could occur more or less close in time, but always within the hourly session. Let's take, as an example, the « request to turn a spinning top ». This request recurred four times during the same observational session. The first time the child made the request she said maman 'mommy' while handling the spinning top to her moter. When the top stopped spinning she picked it up and handed it to her mother saying /tun/ for 'tourne' 'turn', a single-word utterance different from the one used earlier. Somewhat later she made the same kind of request saying maman 
'mommy' while handing the spinning top to her, and on the fourth occasion, just after the spinning top stopped, she said /tupi/ 'toupie' 'spinning top' while handing it to her mother.

Here there are four very similar occurrences of one communicative intention the "request to make the spinning top spin". This communicative intention presents expressive variation since it is expressed by different single-word utterances (maman, tourne, toupie) on at least two of its occurrences.

We will track the emergence of expressive variation by providing the proportion of communicative intentions presenting expressive variation relative to the overall number of communicative intentions that occur at least twice within the same session, and this at each observational session during the defined period.

\subsubsection{Successive-single word utterances (SSWUs)}

A $S S W U$ consists of at least two words semantically related to each other and to a minimal communicative intention. The identification of a communicative intention is based on the ongoing activities, activities occurring just before and after the verbalizations, as well as on information from the dialogue (see Veneziano et al., 1990, p. 635-36, for more details).

SSWUs can be across-turns or within-turn. SSWUs are across-turns when the two related words belong to different turns: the partner intervenes between them or the temporal lag between them is greater than 2 seconds. SSWUs are within-turn whenever the temporal lag between the two words is shorter than two seconds but remains perceptible (greater than .5$)^{3}$. When the intervening pause between the words is not perceptible and the words appear to be pronounced within a single intonational contour, the production is considered a two-word utterance (see also recently, Herr-Israel \& McCune, 2011). 
2.3.3.1. Conversationally-generated SSWUs. All ConG-SSWUs are acrossturn SSWUs. As mentioned above, they are characterized by the fact that the child produces the second single-word utterance of the sequence by relating to the intervening adult's turn. The word may be produced by the imitative uptake of a word contained in the mother's interpretation of the child's initial turn, and different from the one the child had produced initially. This can be seen in example 1 above and in the following example:

Example 7 - ConvG-SSWU: imitative

The child has just placed small plastic toy bottles into a toy plastic basket

Child 1 : /do'do/

'night night'

Mother1: elles font dodo les bouteilles?

'they go night night the bottles?'

Child2 : /'t\|

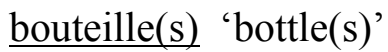

After the production of dodo 'night night' in $\mathrm{C}_{1}$, and the mother's expansion of this child's utterance (addressed as a confirmation request), the child produces in $\mathrm{C}_{2}$ a second word, 'bouteille(s)' 'bottle(s)', related at the same time to the event and to her previous verbalization 'dodo'. 'Bouteille(s)' 'bottle(s)' is the imitative uptake of one of the words contained in the mother's intervening utterance, a word that is different from the one the child had initially produced in $\mathrm{C}_{1}$ (dodo 'night night').

Another kind of ConG-SSWU is one in which the child's production of the second word of the sequence occurs as a reply to a question elicited by the caregiver. An example of elicited ConG-SSWU was provided in example 2 above, and an additional example is provided in example 8 below:

Example 8 - ConvG-SSWU: elicited

The child brings a plastic chip to the mouth of a mechanical frog

Child 1 : /salad/

'salade' 'salad'

Mother1: tu la donnes à qui la salade?

'you give it to whom the salad?' 


\section{Child2: /gu/}

$$
\text { 'grenouille' 'frog' }
$$

In the two kinds of ConG-SSWUs the conversational link between the child's and the adult's turns is different, more primitive in the former case, more mature in the latter. However, in both cases, the child is led to produce the second single-word utterance, meaningfully-related to the previous one, by following the conversation. The meaning relation between the successively produced single-word utterances results from the relation that the secondly uttered word holds with the adult's preceding utterance, which in turn was related to the first single-word utterance of the sequence produced by the child.

2.3.3.2. Child-generated SSWUs. In ChG-SSWUs, the child produces the two single word utterances of the sequence either in two different turns (across-turns) or within the same turn (within-turn), with an intervening pause smaller than 2 secs but larger than .5 secs. Examples 3 and 4 above are both examples of ChG acrossturns SSWUs. Example 9 below is an example of a ChG within-turn SSWU:

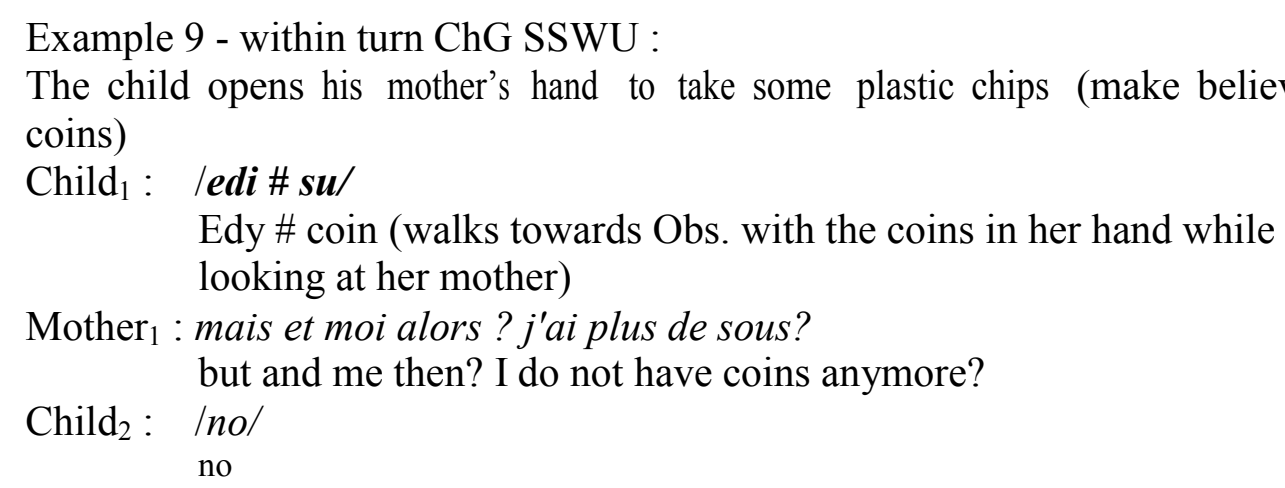

We have seen that in across-turns ChG-SSWUs, the adult may (see example 4 above) or may not intervene between the child's single-word utterances of the sequence (see examples 3 above). However, as seen earlier, if the adult intervenes in a 
ChG-SSWU, that intervention is not determinant for the production of the second word of the sequence since it is neither contained in, nor elicited by that intervention.

As seen above, ChG-SSWUs, both across and within-turn, can find support in previous discourse. These SSWUs are called discourse-sustained. In these ChGSSWUs at least one of the two related words of the sequence has been uttered in anyone of the three previous turns. Three kinds of support were found: a) discoursesustained by other, when at least one of the words of the ChG-SSWU was produced first by the partner in previous discourse. An example of such a sequence can be found in example 5 above and another in example 10 below:

Example 10 - Across-turns ChG-SSWU: discourse-sustained by other The child and the Observer look at a picture book

$\mathrm{Obs}_{1}$ : oh regarde c'est quoi? des pommes? oh look what's that? apples?

Child $_{1}$ : /sa/

this

$\mathrm{Obs}_{2}$ : oui yes

Child $_{2}$ : 位 pom/ (the) apple(s)

In this example, the child produces in $\mathrm{C}_{1}$ the first single-word utterance of the sequence -- ça 'this' -- . The second word of the sequence --'pomme' -- uttered in $\mathrm{C}_{2}$, was produced three turns earlier by the Observer and may be considered to be available to the child's memory and thus to be of easier production at this time.

Another type of discourse-sustained ChG-SSWUs is anchored in the child's own previous production: b) discourse-sustained by the child. It is defined by the fact that at least one of the words of the ChG-SSWU is first produced by the child in one of the three previous turns. An example of such a sequence can be found in example 6 above and another in example 11 below:

Example 11 - Within turn ChG-SSWU: discourse-sustained by child 
The child inserts her hand into a bag (where baby dolls are usually stored) and looks at the Observer

\section{Child ${ }_{1}:$ M'py \# M'py /} (n'est) plus \# (n'est) plus '(isn't) any more \# (isn't) any more'

Child $2:$ Ml'be \#\# II'be \# II'be \#\# I'py/ bébé \#\# bébé \# bébé \#\# (n'est) plus 'baby \#\# baby \# baby \#\# (isn't) any more'

Finally, ChG-SSWUs can be anchored in both the partner and the child's utterances, as shown in example12 below:

Example 12 - Within-turn ChG-SSWU: discourse-sustained by child and by mother

Mother and child sit at the dining table

Mother $_{1}$ : tu veux de l' eau?

Child $_{1}$ 占wal

you want water?

bois/boit ' $\operatorname{drink}(\mathrm{s})$

Mother $_{2}$ : tu veux boire?

you want to drink?

Child 2 : l'lo \# 'bwa:/

l'eau \# bois/boit '(the) water $\operatorname{drink}(\mathrm{s})$ '

Mother $_{3}$ : oui on va boire de l'eau

yes, we are going to drink water

In this example, the ChG-within-turn SSWU is produced in Child 2 (lo\#bwa 'water\#drink). One of its words, /lo/ l'eau, '(the) water', was produced first by the mother three turns earlier (in $\mathrm{M}_{1}$ ), while the other word, /bwa/ 'drink(s)', was produced first by the child two turns earlier (in $\mathrm{C}_{1}$ ) and occurred again a similar form (/bwar/) in $\mathrm{M}_{3}$.

\subsubsection{Multiword utterances}

Multiword utterances were defined as two (or more) related words uttered one after the other with no perceptible pause between them ${ }^{\text {iv }}$. They were distinguished in the same way as within-turn SSWUs and were categorized as 1. discourse-sustained: a) other-sustained; b) child-sustained; c) other- and child-sustained; when at least one 
of the words of the multiword utterance was uttered respectively in one of the adult's, the child's or both the adult's and the child's, three previous turns.; 2. discourseunsustained, when none of the words of the multiword utterance was uttered in one of the three previous turns.

\subsubsection{Reliability measures}

Intercoder reliability was performed on all the above codings. For Expressive options, reliability was measured on the independent analyses of two sessions per child effectuated

by two raters. They obtained $90 \%$ agreement on the coding of communicative intentions, with a Cohen Kappa coefficient of 0.68.

The agreement on the three main utterance categories (single words, SSWUs and multiword utterances) was even higher: $98 \%$ of agreement between the two raters who analyzed half of the sessions from the two children, with a Cohen Kappa coefficient of 0.94 . For the two main kinds of SSWUs, ConvG and ChG-SSWUs, the agreement was $89 \%$ and the Cohen Kappa Coefficient, 0.34 .

\section{RESULTS}

\subsection{Expressive options}

As shown in Figure 1, the girl started using different single-word utterances to verbalize recurrent instances of similar communicative intentions at $1 ; 5$; the boy started showing this behavior at $1 ; 8$.

-Insert Figure 1 about here -

For both children, the number and the proportion of recurring events that find different expressions increased after this point. Let us consider, independently of 
age, the following two developmental periods: 1) the earlier period, up to and including the appearance of expressive options and 2) the later period, after the appearance of expressive options and before that of multiword utterances. For the girl, we compared the observational sessions from age $1 ; 4$ to $1 ; 5$ to those from $1 ; 6$ to $1 ; 7$; for the boy, the sessions when he was aged $1 ; 7$ to $1 ; 8$ to those from $1 ; 9$ to $1 ; 11$. For both children, the difference between the earlier and the later period, tested by a $2 \times 2$ chi-square, is statistically significant (for the girl, $\chi^{2}(1, N=32)=4.09, p<.05$; for the boy, $\left.\chi^{2}(1, N=40)=3.86, p<.05\right)$.

At 1;4 for the girl and at 1;7 for the boy, none of the recurring communicative events were expressed with different words. For example, the girl handed a baby doll to the adult five different times during the observational session, and each time she said /ta/ tiens 'take (it)'; the boy handed a bag containing plastic chips to the mother 6 different times and each time he said /su/ 'coin'. Instead, at 1;5, the girl expressed with different words $22 \%$ of the recurring communicative events, a percentage that increased to $40 \%$ at $1 ; 6$ and to $75 \%$ at $1 ; 7$. For example, she requested her mother to turn the key of a mechanical frog on six different occasions: on three occasions she said /ta/ tiens 'take (it)', in another, /ko/ encore, 'again/more', in another /gu/ grenouille 'frog', and in yet another /tu/ tourne 'turn'; at 1;7, the child tried several times to seat a baby doll on the carpet: on three occurrences, she said /la/ 'there', twice, assis 'seated' and once /la\# a'si/. The boy presents a similar developmental trend. At $1 ; 8,33 \%$ of the recurring communicative events were expressed with different words, a proportion that increased at 1;9 and 1;11 reaching respectively $65 \%$ and $70 \%$. For example, he played a game in which he was giving a plastic chip representing a coin to several toy characters: on two occurrences he said 
/su/ 'coin' on two others 'tiens' 'here (take it)' and on four other occurrences he verbalized the character receiving it ('cow', 'horse', 'doll', 'lady').

It is interesting to note that for both children the first appearance of expressive options coincides with the time at which their cumulative vocabulary ${ }^{\mathrm{v}}$ in production counted about 30 words ( 30 words for the girl and 28 for the boy), and this independently of the age at which this occurs: the girl was aged 1;5 and the boy $1 ; 8$ when expressive options first appeared. Moreover, and again for both children independently of their age, the significant increase in expressive options occurred with an increase in vocabulary. The cumulative number of words was 52 for the girl and 68 for the boy, both significantly greater than expected under a model of linear growth (for the girl, $\chi^{2}(4, \mathrm{~N}=106)=16.25, \mathrm{p}<.01$; for the boy, $\chi^{2}(4, \mathrm{~N}=114)=$ 41.52, $\mathrm{p}<.001)$. It seems that the ability to express similar communicative intentions with different words goes together with a spurt in vocabulary and a greater availability of words to the children, a developmental relation that is made more apparent here by the fact that it occurs in the two children independently of age.

\subsection{Successive single-word and multiword utterances: Developmental sequences}

Figure 2 shows the occurrence of SSWUs, ConvG-SSWUs and ChG-SSWUs, and of multiword utterances for the two children across ages.

For both children, to the exception of sporadic combinations (with ça 'this', or encore 'more' for the boy), SSWUs preceded multiword utterances, a finding in accordance with prediction 2 of the CP Model (see above under 1.5).

- Insert Figure 2 here -

SSWUs appear at 1;9 for the boy and at 1;5 for the girl while multiword utterances were produced more systematically at 2 years by the boy and at $1 ; 8.15$ by 
the girl. For the boy, SSWUs were produced significantly more than multiword utterances in the period between $1 ; 9$ and $1 ; 11$, while the reverse was true in the period between $2 ; 0$ and $2 ; 3\left(\chi^{2}(1, \mathrm{~N}=178)=14.28, \mathrm{p}<.001\right)$. For the girl, the same significant pattern is found when comparing the period between $1 ; 5$ and $1 ; 8$ and that between $1 ; 8.15$ and $2 ; 2\left(\chi^{2}(1, N=471)=208.73, \mathrm{p}<.001\right)$. For the boy, at the last session of the study (at 2;3), multiword utterances were most frequently used to express communicative intentions with at least two words ( $70 \%$ of the latter) but represented only $33 \%$ of all the communicative intentions expressed. For the girl, it was already at 1,9 that multiword utterances were the most frequently used form for the expression of communicative intentions with at least two words (69\%) and at $1 ; 10$ they were already the dominant form of expression overall $(74 \%$ of all communicative intentions).

Concerning the two main kinds of SSWUs, the $2 \times 2$ Chi-square test applied to ConvG and ChG-SSWUs occurring in the first period of SSWUs production and in the later one, is significant for the two children. For the girl, the comparison involved the period $1 ; 5$ to $1 ; 8$ (first period) and that between $1 ; 8.15$ to $2 ; 2$ (second period) $\left(\chi^{2}(1, \mathrm{~N}=116)=29.36, \mathrm{p}<.001\right)$. For the boy, the comparison involved the period between 1;9 and 1;11 (first period) and that between 2;0 and 2;3 (second period) $\left(\chi^{2}(1, \mathrm{~N}=88)=6.87, \mathrm{p}<.01\right)$. For the girl, ConvG-SSWUs were more numerous than ChG-SSWUs in the first period (between 1;5 and 1;8), while in the second period (between $1 ; 8.15$ and 2;2), ChG-SSWUs were more numerous than ConvG-SSWUs. For the boy, ChG-SSWUs were more numerous than ConvGSSWUs in the second period (between 2;0 and 2;3), while in the first period ConvG occurred as much as ChG-SSWUs. Thus, for the two children, the higher production of ChG-SSWUs relative to ConvG-SSWUs occurs together with the more 
systematic production of multiword utterances, suggesting that ChG-SSWUs of the second period may be conceptually close to multiword utterances, to the exception of articulatory fluidity in the production of the component words. In the first period a difference is found between the two children: the boy produces both ConvG and ChG-SSWUs, while the girl relies more on conversation in her production of sequences of SSWUs suggesting that a multiple pathway in the process of creating new relations among words and in revising the relationship between utterances and their meanings.

It should be noted that also Prediction 1 of the CPM is supported by these data. Indeed, expressive options appear at the same session as SSWUs for the girl, and one month earlier for the boy.

\subsection{Successive single-word and multiword utterances: The role of conversation and discourse}

The CP Model predicts that conversation and/or previous discourse play an important role in initiating the change from single to multiword speech. More specifically, it predicts that ConvG-SSWUs and discourse-sustained ChG-SSWUs are produced more in the initial stages, while ChG-SSWUs and multiword utterances not relying on previous discourse become more numerous later.

Figure 3 shows the proportion of ConvG-SSWUs and discourse-sustained SSWUs and multiword utterances, among the communicative intentions expressed by two words, for the two children, developmentally.

- Insert Figure 3 about here -

For the girl, in the first period (between $1 ; 5$ and $1 ; 8$ ), 95\% of these expressions are conversationally-generated or discourse-sustained, while in the second period (between $1 ; 8.15$ and $2 ; 2$ ), this proportion decreases to $43 \%$, the 
difference being highly significant $\left(\chi^{2}(1, \mathrm{~N}=471)=58.29, \mathrm{p}<<.001\right)$. For the boy, the corresponding figures are $53 \%$ in the first period (between $1 ; 9$ and $1 ; 11$ ) and $21 \%$ in the second (between $2 ; 0$ and $2 ; 3$ ), a difference that is statistically significant $\left(\chi^{2}(1, \mathrm{~N}=178)=11.98, \mathrm{p}<.001\right)$. For both children then, the peak of the conversational and/or discourse contribution preceded the first increase in multiword utterances. Moreover, for both children, discourse support decreased greatly just before multiword utterances became the dominant way of expressing communicative events with more than one word.

3.4. Successive single-word and multiword utterances: Temporal distance between the uttered words

Figure 4 shows that the temporal distance between the two related words diminished with development.

- Insert Figure 4 about here -

For both children, in the first period the two related words were produced mostly across-turns: $71 \%$ for the girl and $53 \%$ for the boy. In the second period, these percentages decreased sharply to $24 \%$ for the boy and to $4 \%$ for the girl, related words being then produced mostly as within-turn SSWUs and multiword utterances. The difference between the two periods is statistically significant for both children (for the boy: $\chi^{2}(1, \mathrm{~N}=178)=9.42, \mathrm{p}<.01$; for the girl: $\chi^{2}(1, \mathrm{~N}=471)=$ 205.79, $\mathrm{p}<<.001)$

Within-turn SSWUs and multiword utterances were produced about equally at the time multiword utterances made their systematic appearance (at $1 ; 8.15$ for the girl and at 2;0 for the boy), but subsequently within-turn SSWUs diminished considerably to the profit of multiword utterances that became dominant among the communicative intentions expressed with two (or more) words (see 3.1 above). 


\subsection{Testing the predictions of the CPModel}

The predictions of the CP Model described in 1.5 above are taken up here at the light of the results of the longitudinal studies of the two children.

1) At the time, or soon after, children start expressing similar communicative intentions with different single-word utterances, ConvG- and/or ChG-SSWUs appear. This prediction is confirmed by the data: as soon as both children use different words to express recurrent communicative intentions, they produce ConvGand ChG.SSWUs, For the girl, expressive options appear at 1;5; ConvG- and ChGSSWUs appear at the same session (one occurrence of ConvG-SSWUs is observed already at $1 ; 4)$; for the boy, expressive options appear at 1;8, ConvG- and ChGSSWUs, at 1;9.

2) ConvG- and ChG-SSWUs appear before multiword utterances; with development, SSWUs diminish while multiword utterances become dominant among the communicative intentions expressed with two (or more) words. This prediction is confirmed by he results from the two children: For the girl, ConvGand ChG-SSWUs appear at 1;5 while multiword utterance make their clear appearance at $1 ; 8.15$; at $1 ; 9$ they become the most frequently used form for the expression of communicative intentions with at least two words; SSWUs decrease in that period. For the boy, a similar trend is found, just later in age: ConvG- and ChG-SSWUs appear at 1;9 while multiword utterance make their clear appearance at $2 ; 0$; at $2 ; 3$ they become the most frequently used form for the expression of communicative intentions with at least two words, while SSWUs decrease in the period between $2 ; 0$ and $2 ; 3$.

3) ConvG and discourse-sustained ChG-SSWUs are produced more in the initial stages; ChG-SSWUs and multiword utterances not relying on previous 
discourse become the majority later. Also this prediction is supported by our results. For both children, Conversationally-generated and discourse sustained SSWUs are more numerous in the first period (between 1;5 and 1;8 for the girl; between 1;9 and 1;11 for the boy) while SSWUs and multiword utterances that do not rely on previous discourse are significantly more numerous in the second period (between 1;8.15 and 2;2 for the girl; between 2;0 and 2;3 for the boy).

4) Across-turns ChG-SSWUs appear before within-turn ChG-SSWUs. Also this last prediction is supported by our results. For both children, in the first period, the two related words were produced mostly across-turns, while in the second period, they were produced mostly as within-turn SSWUs and multiword utterances.

\section{DISCUSSION AND CONCLUSIONS}

The Cognitive-Pragmatic Model presented is based on the idea that singleword utterances are a well-anchored behavior and considers that the change from single word to multiword speech requires a conceptual change in the way children apprehend the relationship between communicative intentions and their verbal expression. Instead of a single word, two or more words can be uttered to express one same communicative intention. Within a constructivist approach where discontinuities in development are considered to grow out of underlying continuitiesat the behaviorallevel (e.g., Piaget, 1976/1978; Piaget \& Garcia, 1983/1989), the CP Model proposes that two phenomena, expressive options and co-constructed SSWUs (ConvG-SSWUs and discourse-sustained ChG-SSWUs), provide the initial steps leading children to revise their implicit ideas underlying single-word speech. More specifically, it makes the hypothesis that, in parallel 
with the development in children's ability to entertain different possibilities (e.g., Piaget \& Coll., 1981/1987), children become able to consider more than one aspect of a situation, or of a communicative intention, for verbal expression. This basic development affects children's pragmatic functioning. On the one hand, they start using different single-word utterances to express different occurrences of similar communicative intentions (expressive options); on the other, they become better capable of taking into account and to adjust more finely to the partner's conversational turns allowing the production of SSWUs, conversationally- and child-generated ones. Expressive options and the initial SSWUs contribute to, and are a manifestation of, an emerging new organization among words' meanings and are, for that, predictors of multiword speech.

The specific predictions of the CP Model, based on this theoretical framework, were confirmed by the results of the two longitudinal studies presented. Both children started to use different single-word utterances to express occurrences of similar communicative intentions at around the same time, or just before, they produced their first SSWUs. Also, initial SSWUs relied quite often on conversation or on immediately previous discourse, whereas the later-occurring SSWUs were most often produced without such reliance, suggesting that the ability to use conversational frames to produce SSWUs helps advancing the transition. It may be supposed that children who can take advantage early on of conversation and/or previous discourse to produce SSWUs, should become dominant multiword speakers earlier. In our study, this seems to be the profile of the girl who indeed is ahead of the boy in this development. It seems to fit also the developmental profiles of the more advanced children in Herr-Israel and McCune's study (2011). This is a very interesting point worthwhile investigating closely in future studies. 
Another issue that should be considered more closely and that could throw further light on the role of SSWUs in the production of multiword utterances, is the relation between the particular words uttered in SSWUs and the first multiword utterances produced. This link could be uncovered using the trackback method employed in the study of the relation between multiword utterances and CDS (Lieven et al., 2009). Indeed, SSWUs might incidentally constitute practical exercises for the later production of multiword utterances containing the same kinds of words.

The most original aspect of the CP Model is to situate the initial steps of the transition to multiword speech in new uses of single-word utterances. The appearance of expressive options is supposed to mark a change in the underlying mental organization of word meanings and to provide the initial conceptual step in the transition to multiword speech. Simpler two-turn conversational exchanges in which the child produces one word and the partner a different but related word while talking about the same event, could also feed into this development, as suggested by recent results showing that early multiword utterances have their antecedents in such two-turn exchanges (Gillespie-Lynch, Greenfield, Lyn \& Savage-Rumbaugh, 2011). These sequences, not included in the present CP Model, might indeed be even more primitive forms of precursors than those treated here. They deserve closer investigation in future work and might eventually need to be integrated to the model.

Another interesting aspect that needs further inquiry concerns the relationship between lexical development and multiword speech. Here we found a cooccurrence between the attainment of a certain amount of words (around 30) and the onset of expressive options, the very first transitional phenomenon considered, 
and provided a theoretical framework explaining the reasons for this relationship. Although some studies have investigated the issue with naturalistic data (e.g., Nelson, 1973; McShane, 1980; Dromi, 197; Anisfeld, Rosenberg, Hoberman and Gasparini, 1998) and CDI reports (e.g., Bates, Dale \& Thal, 1995), it deserves further theoretical thought and more precise empirical work taking into account the variety of transitional phenomena discussed in this paper.

Finally, the CP Model, while contributing to a better understanding of the transition to multiword speech, has also important implications for early evaluation and intervention. Situating the initial steps of the transition in the single-word utterances period, it provides new means for evaluating children's development and potentialities for new acquisitions. Thus, the single-word functioning of children who are delayed in the production of multiword speech, or even in the production of SSWUs, might reveal whether they have or not taken the very first steps in the process of change. The $\mathrm{CP}$ Model provides also a precise and articulated framework within which to set up targeted interventions and to identify the areas in which intervention may be most useful for the child at hand. Thus, depending on their specific profiles, for certain children it would be useful helping them to build up vocabulary and to shift their attention to other aspects of a communicative event producing a different verbalization than that used in a previous occurrence. For others, it would be useful to focus on taking into account the partner's turns in conversational exchanges and still for others to provide intensive opportunities to participate in conversations that could give rise to ConvG-SSWUs, the main procedure used in previous intervention studies aiming to promote multiword speech (e.g. Schwartz et al., 1987; Veneziano \& Nieva, 2005). 


\section{Acknowledgements}

This research was carried out thanks to the support of the ANR - French National Research Agency - (EMERGRAM project, for retranscription and video linking, and data analyses) and of the FNRS, the Swiss National Foundation for Scientific Research (for data collection).

We wish to thank Silvia Nieva Ramos for assistance in data analysis.

\section{References}

Acredolo, Linda, P., Goodwyn, Susan, W., Horobin, Karen, D. \& Emmons, Yvonne, D. (1999). The signs and sounds of early language development. In L. Balter and C. Tamis-LeMonda (Eds), Child Psychology: A Handbook of Contemporary Issues. Psychology Press, New York, pp. 116-139.

Anisfeld, Moshe, Rosenberg, Erica S., Hoberman, Mara J. \& Gasparini, Don, 1998. Lexical acceleration coincides with the onset of combinatorial speech. First Language, 18, 165-184.

Antinucci, Francesco \& Parisi, Domenico, 1973. Early language acquisition: a model and some data. In: Ferguson, C. A. \& Slobin, D. I. (Eds.), Studies of Child Language Development. Holt, Rinehart \& Winston, New York, pp. 607-619.

Barrett, Martin, D., 1981. The communicative function of early child language. Linguistics, 19, 273-305.

Barrett, Martin, D., 1989. Early language development. In: Slater, A. \& Bremner, G. (Eds.), Infant Development. Lawrence Erlbaum, London, pp. 211-241.

Bassano, Domenique \& Eme, Pascale E., 2001. Development of noun determiner use in French children: lexical and grammatical bases. In: Almgren, M., 
Barreña, A., Ezeizabarrena, M.J., Idiazabal, I., \& MacWhinney, B. (Eds.), Research on Child Language Acquisition. Cascadilla Press, Sommerville, MA., pp 1207-1220.

Bates, Elisabeth, Dale, Philip. S., \& Thal, Donna, 1995. Individual differences and their implications for theories of language development. In P. Fletcher \& B. MacWhinney (Eds.), The Handbook of Child Language. Blackwell, Oxford, pp. 96-151.

Bloom, Lois, 1970. Language Development: Form and Function in Emerging Grammars. M.I.T. Press, Cambridge, MA.

Bloom, Lois, 1973. One Word at a Time. Mouton \& Co., The Hague.

Bretherton, Inge, 1988. How to do things with one word: The ontogenesis of intentional message making in infancy. In: Smith, M. \& Locke, J. (Eds.), The Emergent Lexicon: The Child's Development of a Linguistic Vocabulary. Academic Press, San Diego, pp.225-260.

Brown, Roger, 1973. A first language. Harvard University Press, Cambridge, MA, USA.

Caselli, Cristina, Casadio, Paola \& Bates, Elizabeth, 1999. A comparison of the transition from first words to grammar in English and Italian. Journal of Child Language, 26, 69-111.

Chomsky, Noam, 1995. The Minimalist Program. MIT Press, Cambridge, MA.

Chouinard, Michelle M. and Clark, Eve V., 2003. Adult reformulations of child errors as negative evidence. Journal of Child Language, 30, 637-669.

Clark, Eve, V., 1997. Conceptual perspective and lexical choice in acquisition. Cognition, 64, 1-37 
Clark, Eve, V., 2009. First Language Acquisition (2nd edition). Cambridge University Press, Cambridge, UK.

Cohen, Marcel, 1952/1969. Sur l'étude du langage enfantin. Enfance 3/4, 203-272.

Cutler, Anne \& Swinney, David A., 1987. Prosody and the Development of Comprehension. Journal of Child Language, 14, 145-167.

Donahue, Mavis, 1986. Phonological constraints on the emergence of two-word utterances. Journal of Child Language, 13, 209-218.

Dore, John, 1975. Holophrases, speech acts and language universals. Journal of Child Language, 2, 21-40.

Dore, John, 1985. Holophrases revisited: their logical development from dialog. In: Barrett, M.D. (Ed.), Children's single-word speech. Wiley \& Sons, Chichester, pp. 23-58.

Dore, John, Franklin, Margery B., Miller, Robert, T. \& Ramer, Andrya L.H., 1976. Transitional phenomena in early language acquisition. Journal of Child Language, 3, 13-28.

Dromi, Esther, 1987. Early lexical development. Cambridge University Press, Cambridge, UK.

Dunn, Judy, 1991. Understanding others: evidence from naturalistic studies of children. In: A. Whiten (Ed), Natural theories of mind. Basil Blackwell, Oxford, pp. 51-61.

Dunn, Judy. \& Munn, Penny, 1987. Development of justification in disputes with mother and sibling. Developmental Psychology, 23, 791-798.

Elbers, Loeki \& Ton, Josi, 1985. Play pen monologues: the interplay of words and babbles in the first words period. Journal of Child Language, 12, 551-565. 
Ferguson, Charles A. \& Farwell, Carol B., 1975. Words and sounds in early language acquisition. Language, 51, 419-439.

Fonagy, Ivan, 1972. A propos de la genèse de la phrase enfantine. Lingua, 30, 31 71.

Galligan, Roslyn, 1987. Intonation with single words: Purposive and grammatical use. Journal of Child Language, 14, 1-21.

Gillespie-Lynch, Kristen, Greenfield, Patricia M., Lyn, Heidi, Savage-Rumbaugh, Sue, 2011. The role of dialogue in the ontogeny and phylogeny of early symbol combinations: A cross-species comparison of bonobo, chimpanzee, and human learners. First Language. Published online June 2011, DOI: 10.1177/0142723711406882.

Goldberg, Adele E., 1995. Constructions : A Construction Grammar Approach to Argument Structure. The University of Chicago Press, Chicago.

Greenfield, Patricia M. \& Smith, Michael, 1976. The Structure of Communication In Early Language Development, Academic Press, Chicago.

Herr-Israel Ellen, \& McCune Lorraine, 2011. Successive single-word utterances and use of conversational input: a pre-syntactic route to multiword utterances. Journal of Child Language, 38, 166-180.

Ingram, David, 1971. Transitivity in child language. Language, 47, 888-910.

Ingram, David, 1979. Stages in the acquisition of one-word utterances. In: French, P. (Ed.), The Development of Meaning. Bunka Hyoron, Hiroshima, pp. 256281.

Kilani-Schoch, Marianne \& Dressler, Wolfgang U., 2001. Filler+Infinitive and Pre\& Protomorphology demarcation in a French acquisition corpus. Journal of Psycholinguistic Research, 30, 653-685. 
Lieven, Elena V. M. (1984). Interactional style, and children's language learning. Topics in Language Disorders, 4, 15-23.

Lieven, Elena, Salomo, Dorothée, \& Tomasello, Michael, 2009. Two-year-old children's production of multiword utterances: A usage-based analysis. Cognitive Linguistics, 20(3), 481-507.

López Ornat, Susana, 2001. Fillers: how much do they generalize?. Journal Child Language, 28, 266-268.

MacNeilage, Peter F. \& Davis, Barbara L., 2000. Evolution of speech: The relation between ontogeny and phylogeny. In: Knight, C., Hurford, J. R. \& StuddertKennedy, M. (Eds), The Evolutionary Emergence of Language: Social Function and the Origins of Linguistic Form. Cambridge University Press, Cambridge, pp.146-160.

Matthei, Edward, 1989. Crossing boundaries: More evidence for phonological constraints on early multi-word utterances. Journal of Child Language 16, 4154.

McNeill, David, 1970. The Acquisition of Language: The Study of Developmental Psycholinguistics. Harper \& Row, New York.

McShane, John, 1980. Learning to talk. Cambridge University Press, Cambridge, UK.

Ninio, Anat, 1992. The relation of children's single word utterances to single word utterances in the input. Journal of Child Language, 19, 87-110.

Ninio, Anat, 1994. Expression of communicative intents in the single-word period and the vocabulary spurt. In: Nelson, K. \& Reger, Z. (Eds.), Children's Language, Vol. 8. Erlbaum, Hillsdale, NJ, pp. 103-124. 
Ninio, Anat \& Snow, Catherine E., 1996. Pragmatic Development. Westview Press, Boulder, CO.

Ochs, Elinor, Schieffelin, Bambi B. \& Platt, Martha L., 1979. Propositions across utterances and speakers. In: Ochs, E. \& Schieffelin, B.B. (Eds.), Developmental Pragmatics. Academic Press, New York, pp.251-268.

Peters Ann M. \& Menn, Lise, 1993. False starts and filler-syllables: Ways to learn grammatical morphemes. Language, 69, 742-777.

Piaget, J. (1976/1978). Le comportement, moteur de l'évolution. Gallimard, Paris. (English translation: Behavior and evolution. Pantheon Books, New York, 1978).

Piaget, Jean \& Coll., 1981/1987. Le Possible et le Nécessaire. Vol. 1: L'évolution des Possibles chez l'Enfant. P.U.F., Paris. (English translation: Possibility and Necessity. Vol.1: The Role of Possibility in Cognitive Development. University of Minnesota Press, Minneapolis, 1987).

Piaget, Jean \& Garcia, Rolando, 1983. Psychogenèse et histoire des sciences. Flammarion, Paris. (English translation: Psychogenesis and the History of Science. Columbia University Press, New York, 1989).

Rodgon, Maris Monitz, 1976. Single-word usage, cognitive development and the beginnings of combinatorial speech. Cambridge University Press., Cambrisge, U.K.

Sachs, Jacqueline, 1983. Talking about the there and then: The emergence of displaced reference in parent-child discourse. In: Nelson. K. E. (Ed.), Children's language. Erlbaum, Hillsdale, NJ, Vol. 4, pp. 1-28. 
Schwartz, Richard, G., Chapman, Kathy, Prelock, Patricia, A., Terrell, Brenda,Y. \& Rowan, Lynne, E., 1985. Facilitation of early syntax through discourse structure. Journal of Child Language, 12, 13-25.

Scollon, Ron, 1979. A real early stage: an unzippered condensation of a dissertation on child language. In: Ochs, E. \& Schieffelin, B.B. (Eds.), Developmental Pragmatics. Academic Press, New York, pp. 215-227.

Shatz, Marilyn, 1978. The relationship between cognitive processes and the development of communication skills. In: Keasey, C. B. (Ed.), Nebraska Symposium on motivation. University of Nebraska Press, Lincoln.

Shatz, Marilyn, 1994. A Toddler's Life: Becoming A Person. Oxford University Press, New York, NY.

Smith, B. L., 1988. The emergent lexicon from a phonetic perspective. In: M. Smith \& J. Locke J (eds.), The Emergent Lexicon. Academic Press, New York, pp. 75-109.

Snow, Catherine E., 1978. The conversational context of language acquisition. In: Campbell, R.N. \& Smith, P.T. (Eds), Recent advances in the psychology of language: language development and mother-child interaction. Plenum Press, New York, pp. 253-269.

Taelman, Helena, Durieux, Gert, \& Gillis, Steven, 2009. Fillers as signs of distributional learning. Journal of Child Language, 36, 323-353.

Tesnière, Lucien, 1959. Eléments de Syntaxe Structurale. Editions Klincksieck, Paris.

Thelen, Esther, 1991. Motor aspects of emergent speech: A dynamic approach. In N. A. Krasnegor, D. M. Rumbaugh, R. L., Schiefelbusch, \& M. Studdert- 
Kennedy (eds.), Biological and Behavioral Determinants of Language

Development. Lawrence Erlbaum Associates, Hillsdale, NJ, pp. 339-362.

Tomasello, Michael, 2003. Constructing a Language: A Usage-Based Theory of

Language Acquisition. Harvard University Press, Cambridge, MA.

Veneziano, Edy, 1999. Early lexical, morphological and syntactic development in

French : Some complex relations. Journal of Bilingualism, 3 (2), 183-217.

Veneziano, Edy, 2001. Interactional processes in the origins of the explaining

capacity. In : Nelson, K., Aksu-Koc, A. and Johnson, C. (Eds.), Children's

Language, Vol. 10. L. Erlbaum, Mahwah, N.J., pp. 113-141.

Veneziano, Edy, 2004. The emergence of expressive options in early child language: A constructivist account. In: Ravid, D. \& Bat-Zeev Shyldkrot, H. (Eds), Perspectives on Language and Language Development: Essays In Honor of Ruth A. Berman. Springer, Dordrecht, pp. 203-218.

Veneziano, Edy \& Nieva Ramos, Silvia, 2005. The first steps towards word combination: The contribution of conversation. Paper presented at ELA 2005, Lyon, France.

Veneziano, Edy \& Parisse, Christophe (2010). The acquisition of early verbs in French: Assessing the role of conversation and of child-directed input. First Language, 30, 287-311.

Veneziano, Edy \& Sinclair Hermine, 1995. Functional changes in early child language: the appearance of references to the past and of explanations. Journal of Child Language, 22, 557-581.

Veneziano, Edy \& Sinclair Hermine, 2000. The changing status of 'filler syllables' on the way to grammatical morphemes. Journal of Child Language, 27, 461500. 
Veneziano, Edy, Sinclair, Hermine \& Berthoud, Ioanna, 1990. From one word to

two words: repetition patterns on the way to structured speech. Journal of

Child Language, 17, 633-650.

Werner, Heinz, \& Kaplan, Bernard, 1963. Symbol formation: An organismic developmental approach to language and the expression of thought. John Wiley, New York.

\section{NOTES}

\footnotetext{
${ }^{\mathrm{i}}$ The symbol \#\# indicates a silence greater than 1 second and less or equal to 2 seconds.

ii We thank the FNRS, the Swiss National Foundation for Scientific Research, for support during data collection.

${ }^{\text {iii }}$ Pauses were measured with a digital stopwatch. The pause retained (between two words produced by the child without the intervention of another speaker) had to be obtained in three measures of the pause. ${ }^{\text {iv }}$ The utterance containing only a content word preceded by a filler (e.g., / $\partial$ siñ/ ' $\partial$ swan'), an article or a pronoun (e.g., un livre 'a book',; elle saute 'she jumps'), was not counted as multiword utterance, nor were the few formulaic expressions found for these children (/le'la/ (il est)-là '(it's)-there', /il'c'u/ il-estoù 'where-is-that' and /søkwa'sa/ c'est-quoi-ça 'what's-that'). Until evidence for the independent status of the components was found, they were considered single-word utterances.

${ }^{v}$ As mentioned in 2.3.1, were counted as words all vocal production phonologically similar to a word of the language and whose meaning was shared by the child and at least his/her caretaker. These productions consist of all word categories including proper names (very few in these two samples). Cumulative vocabulary was computed by counting the number of NEW words at the session under scrutiny (words not already encountered in previous sessions) and adding them to the cumulative number of words of the previous session. For the first session of the study, the number of words, the number of new words and the cumulative number of words at the session all coincide.
} 


\section{Figures Captions}

Figure 1 - Proportion of recurrent events expressed by different words (expressive options) by age and by child : a) for the boy b) for the girl.

\section{Figure 2 -}

Figure 2 - Occurrence of SSWUs (ConvG-SSWUs, ChG-SSWUs and total) and of multiword-utterances, by age and by child: a) for the boy b) for the girl

Figure 3 - Proportion of SSWUs and multiword utterances that are conversation and/or discourse supported, by age and by child: a) for the boy b) for the girl.

Figure 4 - Number of SSWUs - across-turns and within-turn - and of multiword utterances, by age and by child: a) for the boy b) for the girl 